\title{
A Organização (in)corporada: ontologia organizacional, poder e corpo em evidência
}

\author{
The (in)corporated organization: organizational ontology, power, and body in evidence
}

Eloisio Moulin de Souza ${ }^{1}$

Universidade Federal do Espírito Santo / Centro de Ciências Jurídicas e Econômicas, Vitória - ES, Brasil

Alessandra de Sá Mello da Costa ${ }^{2}$

Pontifícia Universidade Católica do Rio de Janeiro / Departamento de Administração, Rio de Janeiro - RJ, Brasil

Severino Joaquim Nunes Pereira ${ }^{3}$

Universidade Federal Rural do Rio de Janeiro / Instituto Multidisciplinar de Nova Iguaçu, Departamento de Administração e Turismo, Nova Iguaçu - RJ, Brasil

\section{Resumo}

Este artigo tem por objetivo problematizar o significado de organização por meio de uma abordagem construcionista. Para tanto, foi realizado um estudo bibliográfico sobre o tema, cujo principal objetivo é analisar as diferenças entre os debates realista e construcionista sobre a ontologia organizacional. Verifica-se que o conceito de organização se torna bem mais amplo nas abordagens construcionistas, não se limitando ao estudo de temas relacionados exclusivamente a empresas, trabalho ou indústrias. Nesse sentido, para problematizar os principais aspectos construcionistas relacionados ao conceito de organização, considera-se o estudo do corpo um dos temas pertencentes aos estudos organizacionais, correlacionando esse tema aos processos de organizing, processos estes constituídos por relações de poder que perpassam todo o corpo social, ou seja, que ocorrem além das fronteiras de uma empresa. Dessa forma, o objeto de análise dos estudos organizacionais passa a ser o organizing e não as organizações. Para entender como esses processos de organizing ocorrem, é necessário considerar que objetos, sentidos, significados, "realidades" e "verdades" são socialmente construídos e não existem a priori ou pré-discursivamente.

Palavras-chave: Ontologia. Organizing. Corpo. Construcionismo social. Poder.

\section{Abstract}

This article aims to discuss the meaning of organization through a constructionist approach. To do this, we conducted a bibliographic study on the theme, whose main aim is analyzing the differences between the realist and constructionist debates about organizational ontology. It is observed that the concept of organization becomes much broader in constructionist approaches, not limited to studying themes related only to companies, work, or industries. In this sense, to discuss the main constructionist aspects related to the concept of organization, the study on the body is regarded as

Artigo submetido em 23 de março de 2014 e aceito para publicação em 26 de novembro de 2014.

DOI: http://dx.doi.org/10.1590/1679-395118624

${ }^{1}$ Doutor em Psicologia pela Universidade Federal do Espírito Santo; Professor Adjunto da Universidade Federal do Espírito Santo. Endereço: Av. Fernando Ferrari, 514, Goiabeiras, CEP 29075-910, Vitória - ES, Brasil. E-mail: eloisiomoulin@gmail.com

2 Doutora em Administração pela Fundação Getulio Vargas/EBAPE; Professora Adjunta do Departamento de Administração da Pontifícia Universidade Católica do Rio de Janeiro (IAG/PUC Rio). Endereço: Rua Marquês de São Vicente, 225 - Prédio IAG Gávea, CEP: 22451-900, Rio de Janeiro - RJ, Brasil. E-mail: alessandra.costa@iag.puc-rio.br

${ }^{3}$ Doutor em Administração pela Fundação Getulio Vargas/EBAPE; Professor Adjunto do Departamento de Administração e Turismo do Instituto Multidisciplinar de Nova Iguaçu da Universidade Federal Rural do Rio de Janeiro. Endereço: Av. Governador Roberto Silveira, S/N, Centro, CEP: 26020-740, Nova Iguaçu - RJ, Brasil. E-mail: bill.pereira4@gmail.com 
one of the themes belonging to organizational studies, correlating this theme to organizing processes, which are constituted by power relations that permeate the whole social body, i.e. they occur beyond the boundaries of a company. Thus, the object of analysis of organizational studies becomes organizing, instead of organizations. To understand how these organizing processes occur, there is a need to consider that objects, senses, meanings, "realities" and "truths" are socially constructed and they do not exist a priori or pre-discursively.

Keywords: Ontology. Organizing. Body. Social constructionism. Power.

\section{Introdução}

Um dos mais significativos debates contemporâneos em estudos organizacionais diz respeito ao próprio significado de organização. Sobre esse aspecto Westwood e Clegg (2003) e Reed (1998) enfatizam que os estudos organizacionais são um terreno discursivamente contestado, dentro do qual coexistem uma variedade de vozes engajadas em um imbricado processo político de aclamação por reconhecimento, aceitação e dominação. Isto é, vozes "[...] por meio das quais o campo de estudos organizacionais é constituído enquanto prática intelectual dinâmica, permeada de controvérsias teóricas e conflitos ideológicos em torno da questão de como a 'organização' pode e deve ser" (REED, 1998, p. 66). De uma forma mais específica, esse debate pode ser entendido como uma discussão que também envolve embates e lutas ontológicas e epistemológicas; principalmente, entre perspectivas realistas e construcionistas, o que torna a definição sobre o que é uma organização algo múltiplo e heterogêneo (BOAL, HUNT e JAROS, 2003; CZARNIAWSKA, 2003; DONALDSON, 2003).

Com o intuito de enriquecer esse debate, este artigo procura problematizar o significado de organização recorrendo a uma análise construcionista (segundo a qual objetos, sentidos, significados, "realidades" e "verdades" são socialmente construídos, não existindo a priori ou pré-discursivamente). O argumento apresentado é o de que o corpo deve ser visto como um tema de análise pertencente também ao campo dos estudos organizacionais. Nesse sentido, o artigo procura desvelar possíveis implicações acerca dessa premissa sobre o conceito de organização.

Para tanto, se faz necessário entender o que é uma organização e quais seus significados; inquietação que nos leva também a considerar aspectos ontológicos e epistemológicos nessa análise, bem como a explorar as definições sobre o que é o corpo. Somente a partir dessas análises, podemos entender as relações entre corpo e organização. Como ressalta Porter (1992, p. 313), pensar de forma crítica o corpo e "seus perigos, suas disciplinas, seu potencial para a profanação, mas também seus poderes produtivos" nos permite melhor compreender as idiossincrasias das disciplinas modernas.

Este artigo começa o debate discutindo, em sua primeira seção, aspectos relacionados à ontologia e à epistemologia organizacional, procurando-se entender o que é uma organização, nas perspectivas realistas e construcionistas sociais. A segunda seção apresenta as relações entre corpo e organização, para consolidar o estudo do corpo como um tema pertencente aos estudos organizacionais. A terceira seção analisa o significado de corpo, procurando evidenciar o rompimento com um conceito de corpo determinado pelo biológico e a emergência da ideia de um corpo contextualmente constituído. Por fim, são apresentadas as principais conclusões do artigo.

\section{Ontologia e Epistemologia Organizacional}

Westwood e Clegg (2003) argumentam que organização é uma produção discursiva, pela qual se opera uma relação saber-poder (FOUCAULT, 2003). Dessa forma, como todas as formas de discurso, a definição de organização funciona por meio de práticas de inclusão e exclusão. Nesse aspecto, os estudos organizacionais 
não podem ser representados como um discurso coerente, homogêneo e abrangente (WESTWOOD e CLEGG, 2003). Pelo contrário, os discursos são parciais, inconsistentes e incompletos. Dentre os diversos discursos organizacionais iremos nos concentrar em analisar o realismo, presente tanto no positivismo quanto no funcionalismo, e o construcionismo social. Comecemos esse debate com o realismo.

A partir de uma perspectiva ontológica (que discute e problematiza a natureza da realidade), o realismo considera a realidade algo objetivo e singular. Segundo Burrell e Morgan (1979), essa objetividade assume ao mesmo tempo uma visão determinística da natureza humana e a utilização de um método nomotético (que enfatiza a técnica, a sistematização, a quantificação e testes de hipóteses).

Boal, Hunt e Jaros (2003) defendem uma visão realista de organização e acreditam que organizações, assim como árvores, rochas e gravidade, são reais em suas consequências; ou seja, para eles organizações são entidades. É nesse sentido que o realismo baseia-se na crença da real existência das coisas, mesmas aquelas que não são empiricamente observáveis e confirmáveis por meio de probabilística. Em outras palavras, a realidade existe independente da percepção que os sujeitos têm dela. Segundo Westwood e Clegg (2003), a abordagem realista defende que o discurso é um serviçal da ciência, capaz de correções incrementais na direção da "verdade", sempre chegando o mais perto possível da "realidade" dos objetos, os quais têm existência própria.

No que se refere às perspectivas epistemológicas positivistas e funcionalistas, ao compararmos o positivismo (CUPANI, 1985) com as características do funcionalismo descritas por Boal, Hunt e Jaros (2003), verificamos que ambos apresentam claramente uma visão realista de mundo.

Segundo Donaldson (2011), as teorias sociais positivistas explicam o comportamento a partir do que causa situações que forçam os indivíduos a agir de certa forma (às vezes, contra sua vontade), conforme as pressões do ambiente. Nas teorias organizacionais, o positivismo explica aspectos da organização ou de seus membros por meio da sua situação ambiental. Generalização, objetivismo, determinismo e realismo: o positivismo na ciência organizacional busca criar teorias gerais sobre as organizações e seus membros, com base nas leis universais das ciências naturais. O objetivo é revelar regularidades causais que existem sob a superfície da realidade. Nesse sentido, a explicação surge e se sustenta, primeiro de tudo, nos termos de causas que determinam efeitos. Ainda de acordo com esse autor, de forma bastante complementar, o funcionalismo defende que a estrutura social é moldada pelo imperativo da adaptação, de forma a prover necessidades sociais fundamentais. Os benefícios de alguns aspectos da estrutura social não são aparentes para os membros da sociedade. Isto é, são funções latentes, de modo que as funções têm características objetivas (DONALDSON, 2011).

De acordo com Burrell e Morgan (1979), o funcionalismo (cujas raízes residem no positivismo sociológico) tem gerado hegemônicos modelos de análise das organizações com abordagens fundamentadas em explicações racionais das questões sociais, tais como status quo, ordem social, consenso, integração social, solidariedade, satisfação das necessidades e realidade. Em sua forma de compreensão da realidade, três ideias são centrais: sistema, organismo e função. Assim, o pensamento funcionalista sistêmico envolve: (a) a noção de sistema e a concepção de sociedade como um sistema social; (b) a apropriação de metáforas comparativas de tais sistemas com os sistemas orgânicos das ciências naturais, caracterizando a existência de "leis sociais naturais"; e (c) a concepção das categorias funcionais necessárias à manutenção da estabilidade relativa de tais sistemas.

Assim, vemos a presença do realismo no positivismo quando o positivismo afirma que o conhecimento só é válido se for intersubjetivo, ou seja, objetivo no sentido dos resultados não variarem em função do pesquisador. Ao contrário do que Boal, Hunt e Jaros (2003) afirmam, o positivismo não busca somente predizer, mas, da mesma forma que o funcionalismo, explicar e predizer (CUPANI, 1985). Ambos, positivismo e funcionalismo, não valorizam o singular e a subjetividade humana em suas análises. Desse modo, o realismo é uma característica não somente do funcionalismo, mas também do positivismo. 
Contudo, o que seria uma organização para o realismo? Em uma visão realista, a organização é um objeto, ou seja, uma "coisa" no sentido durkheimiano do termo. De acordo com Vergara e Caldas (2005, p. 67), para os funcionalistas, "as organizações são objetos tangíveis, concretos e objetivos". Portanto, da mesma forma que os fatos sociais, as organizações têm vida própria e não dependem da subjetividade humana para existirem e agirem. Em outras palavras, organizações são entidades e como tais têm vontades e desejos próprios, independentes de qualquer sujeito humano. Afirmar que organização é uma entidade é dizer que a organização tem existência pré-discursiva.

Donaldson (2003, p. 118) compartilha dessa visão em que organizações são entendidas como entidades, e expressa essa posição quando afirma que estas "são fatos sociais na medida em que são externas aos indivíduos e os moldam [...] e têm uma existência objetiva e os moldam [tendo] uma existência objetiva. A sua existência não depende do indivíduo desejar sua existência ou necessariamente percebê-las [...]”. O fato social impacta o indivíduo, independentemente da vontade do mesmo ou do individuo o reconhecer como um fato social. Entretanto, cabe ressaltar que, como argumenta Reed (1998, p.84), a "epistemologia positivista restringe severamente o limite do conhecimento que pode ser atingido pelos estudos organizacionais, limitando-o àqueles fatos que podem ser submetidos a um método de prova rigoroso, bem como a generalizações semelhantes a leis que ela sanciona".

Uma vez explicado o significado de organização para o realismo, seja funcionalista ou positivista, o que seria organização para o construcionismo? Para responder a essa questão, iremos explicar antes de tudo o que é construcionismo.

Diferentemente do realismo, pode-se entender a realidade não como objetiva e singular, mas como subjetiva e múltipla. A perspectiva epistemológica do construcionismo assume essa visão ontológica: o mundo e seus objetos são entendidos construções sociais, ao invés de serem apenas obras da natureza, podendo ser conhecidos a partir do foco nos diferentes processos de interação social. Dessa forma, "enfatiza a riqueza dos múltiplos discursos, destacando o que acontece entre as pessoas em suas interações e como se dá a construção de sentidos nessas relações [...] [Portanto] os discursos dos indivíduos a respeito de um fenômeno são tidos como caminhos de análise do próprio fenômeno" (MARRA e BRITO, 2011, p. 3).

Nesse sentido, existem para Czarniawska (2003) duas formas de construcionismo nos estudos organizacionais: (1) o construcionismo social, significando um processo onde algo está sendo construído para fora da existência material, no qual utiliza-se a palavra construção em oposição ao uso das palavras criação e descoberta; e (2) construção como um objeto social produzido pelas pessoas, com atributos que podem ser descritos e até mesmo mensurados, partindo-se da crença de que pessoas constroem suas opiniões e representações em interações com outras pessoas, processo este denominado de representações sociais (Teoria das Representações Sociais - TRS).

Na primeira perspectiva apresentada por Czarniawska (2003), a palavra social não se aplica apenas a seres humanos; ou seja, não se refere apenas a pessoas, mas também a objetos. Nesse sentido, a construção social ocorre em uma interação constante entre humanos e não humanos, como descrevem Foucault (1999a) e Latour (1999). Na segunda perspectiva de construcionismo, os pesquisadores não estão interessados em explicar como as representações são construídas, mas em como as representações são objetificadas pelas pessoas. Isto é, a palavra social refere-se apenas a pessoas, como, por exemplo, trabalha a TRS desenvolvida por Moscovici (1978). Entretanto, um ponto comum entre as duas abordagens construcionistas apresentadas é que ambas não intentam formular leis ou predizer fenômenos.

É nesse sentido que o construcionismo social assume uma perspectiva ontológica sobre as organizações diferente do realismo. Ele tem como principal argumento que as organizações não devem ser entendidas como entidades sociais concretas, "melhor compreendidas como um resultado agregador, não intencional, de esforços locais de ordenar e regular nosso amorfo e intratável cotidiano para torná-lo mais previsível e habitável” (CHIA, 2003, p. 98). Em outras palavras, “organização é mais um processo tedioso e interminável 
de tangibilizar o real do que algo sólido e estático" (CHIA, 2003, p. 98). Dessa forma, a visão construcionista sobre organização é bem mais ampla do que a realista, ou seja:

\begin{abstract}
Estudos Organizacionais (EO) não como o estudo de "organizações", mas como a analise sustentada de genéricos impulsos organizacionais que moldam contemporâneos modos de análise, códigos de comportamentos, maneirismos sociais, vestuários, gestos, posturas, normas jurídicas, disciplinas do conhecimento e assim por diante. Esses micro processos de ordenação coletiva servem para moldar nossas identidades e aspirações e para nos orientar em relação a nós mesmos e ao nosso contexto (CHIA, 2003, p. 98)
\end{abstract}

Dessa forma, o construcionismo entende organizações como um processo emergente, ao invés de um fenômeno estável ou entidade. Como afirmam Vergara e Caldas (2005, p. 67), a ideia é entender que "as organizações são verbos, não substantivos". Portanto, as organizações estão sempre em processo de tornarem-se (becoming) organizações, processo este em constante movimento, nunca finalizado.

Chia (2003, p. 100) defende que as organizações podem ser entendidas como "ilhas de ordem interacional de padrões relativamente estáveis, captadas seletivamente de um mar de caos", que não possuem características pré-definidas e, sim, características que se formam no dia a dia em curso. Como desdobramento, não há existência pré-discursiva de organização para o construcionismo. Pode-se afirmar, então, que a organização não tem existência própria, a priori, não se constituindo como um objeto natural ou uma entidade neutra e ahistórica. Toda organização é uma construção histórica, social e cultural envolvida por relações de poder.

Cooper (1986) esclarece que o significado de organização é algo precário, existindo uma "indecibilidade" entendida aqui como ausência de certezas e de critérios de verdade - sobre ele. Isto é, trata-se de um estado dinâmico, um processo, onde sempre haverá espaço para a falta de existência de ordem específica, organização ou direção: um processo de indecisão que perverte toda organização social. Assim, a organização só existe se trouxer consigo a desorganização, não havendo um centro na estrutura, pois todo centro não tem local natural, ou um locus fixo, mas um não lugar no qual um infinito número de signos podem vir a substituir seu sentido. Portanto, só há organização se existir concomitantemente desorganização. Toda organização é um movimento que sempre estará inacabado e incompleto, pelo qual a organização plena nunca será atingida. Cooper enfatiza assim a ideia de que organização é um processo (organizing) e não um estado ou objeto fixo. De forma complementar, Munro (2001, p. 395) diz que o que Cooper chama de organização "é sempre a organização da organização [no original: is always the organisation of organisation']".

Ainda segundo Cooper (2007), processo nos faz pensar as organizações como transmissões de eventos mutáveis, ao invés de estruturas estáveis, onde estrutura e objetos passam a ser considerados secundários para movimentar esse processo. Pensar as organizações como processo requer que não as vejamos mais como formas acabadas ou sistemas completos. Ao invés disso, organizações passam ser consideradas móveis, provisórias, inacabadas e incompletas, e esse conceito de organização substitui a análise da estrutura pelo estudo do processo; ou seja, processo é o oposto de estrutura. Conforme Thanem (2001), essa forma de entender as organizações produziu uma descontinuidade entre as abordagens convencionais da administração que consideram organização uma entidade "natural" e os estudos que problematizam o conceito de organização analisando os processos que organizam a vida social como um todo.

Portanto, sempre onde houver relações de poder buscando ordenar a vida haverá organização. Desse modo, organização não significa empresa ou entidade, mas refere-se ao ato de organizar, ordenar, como, por exemplo, os corpos, os gestos, as vestimentas, as subjetividades, os desejos, a vida, cabendo observar que esse processo de organizar não envolve somente seres humanos e que não acontecem somente em relações de trabalho ou dentro de empresas. Onde há poder ocorre ordenação, produção e classificação social. Somente existe organização onde há poder; ou seja, organização significa poder, ordem e controle. Assim, para o construcionismo, o termo organização é entendido como microprocessos de ordenamento, cuja 
ocorrência e análise não se restringem somente a empresas, apesar de muitos processos de ordenamento também ocorrerem em empresas. Isto é, os estudos organizacionais têm como objeto de análise os processos de ordenamento e não empresas. Nesse sentido, tendo-se explicado o significado de organização empregado neste artigo, será debatido nas próximas sessões a relação entre corpo e os estudos organizacionais, bem como os principais conceitos sobre o corpo e sua relação com o poder e o organizing.

\section{(In)Corporando os Estudos Organizacionais}

A preocupação com o corpo (e o seu papel) nos estudos de administração não é algo novo ou recente. Desde o início do século XX, Frederick Taylor, com o estudo dos tempos e movimentos, e Henry Ford, com a linha de montagem, já tinham como principal tema de análise o corpo, intentando aperfeiçoar seu controle para aumentar a produção. Parker (2000), por exemplo, descreve que o fordismo é uma manipulação sistemática do músculo humano. Até nas premissas da abordagem das relações humanas identifica-se essa preocupação, pois, partindo da ideia de que existe uma divisão entre corpo e mente, seus teóricos e pesquisadores buscaram elaborar formas de controle dos corpos, controlando a mente dos trabalhadores pela gestão de grupos informais a que estes pertenciam.

De acordo com Morgan (1996, p. 43), mesmo a partir de perspectivas mais recentes "é possível pensar nas organizações como se fossem organismos". Segundo Abbagnano (2007) pode-se definir organismo como um corpo vivo onde toda a sua estrutura está subordinada a sua função de sobreviver como organismo. Ao mesmo tempo, cada uma das suas partes subordina-se ao todo e (assim como a totalidade) tem uma finalidade (estrutural) própria.

Para Dale e Burrell (2000), o processo de racionalidade descrito por Weber e o desenvolvimento da ciência ocidental não objetivavam somente o controle do Homem sobre a natureza, mas também o controle do corpo. Não é por acaso que o termo organização encontra sua metáfora explanatória na biologia, já que as "ideias de estrutura, função e limites são comuns tanto à visão biológica do corpo quanto à ideia da 'organização' em si. A natureza limitada do corpo passa a ser construída por meio de teorias biológicas" (Ibid., p. 20). É nesse sentido que se pode argumentar que foi o uso da biologia na concepção de organização que tornou a estrutura um conceito padronizado, ordenado e "natural" para a teoria organizacional. "[Assim], de certa forma, podemos dizer que as teorias organizacionais e biológicas recorrem a um conjunto comum de ideia de corporalidade e [que] ambas tentam criar seu próprio objeto teórico" (Ibid., p. 20).

Ainda de acordo com estes autores, as organizações, em uma perspectiva funcionalista, são teorizadas como estruturas autodeterminadas, como organismos biológicos. Dessa forma, vemos que o conceito de organização como entidade apresentado anteriormente só pode existir se fundamentado na biologia. Além disso, o conceito de racionalidade existente nessas teorias fundamenta-se na noção de corpo organizado, principalmente, apoiando-se na divisão cartesiana clássica entre corpo e mente. Essa divisão, como destaca Flores-Pereira (2010, p. 423), "acaba por gerar um sentido de funcionalidade e instrumentalidade do corpo humano: o corpo como um objeto a serviço das pessoas e, no caso, a serviço da eficiência e eficácia das organizações". É por isso que uma organização racional requer que as pessoas tornem-se partes previsíveis do todo, existindo a suposição de que " os membros da organização atuarão como "membros" - no sentido de mãos, membros, apêndices, ferramentas. [E um] membro biológico não é um cérebro" (DALE e BURRELL, 2000, p. 22).

Dale e Burrell (2000, p. 24) afirmam ainda que "a organização, quando a legitimidade de seu status ontológico é questionada, é tratada como se fosse um indivíduo, e os indivíduos que a compõem, por sua vez, tornam-se suas partes ou seus membros [órgãos]". De forma semelhante, a visão biológica modernista sobre o corpo e as relações entre a organização e seus membros também são vistas como mecânicas, apesar 
de ironicamente a organização ser conceituada como um organismo. Por isso, a estrutura torna-se algo importante, pois se chegando à estrutura correta atinge-se o equilíbrio entre todas as partes.

Portanto, o corpo não é um tema estranho aos estudos organizacionais (FLORES-PEREIRA, 2010). Mesmo as abordagens clássicas e funcionalistas falam sobre o corpo em seu conceito de organização/entidade. Contudo, o corpo é tratado como metáfora de uma estrutura delimitada perfeita; estrutura essa a ser imitada pelas organizações em suas relações com o ambiente, ou como um apêndice da máquina que deve ser controlado para que a organização atinja sua máxima performance. Em ambas concepções, entretanto, a percepção é a mesma: o corpo é considerado inerte e passivo (LETICHE, 2000). Enfim, corpo como metáfora ou apêndice é considerado fator de primeira ordem para a sobrevivência das organizações.

O que se defende neste artigo é que o corpo deve ser considerado um tema mais presente na área de estudos organizacionais, não porque sirva como metáfora ou apêndice, mas porque é uma construção social e histórica ativa, envolvida e permeada por relações de poder, configurando-se por um processo de ordenamento (organizing) que não se limita somente às fronteiras de uma empresa. Dessa maneira, organizações não são entidades, mas construções sociais e históricas em constante movimento, sempre inacabadas e incompletas, sendo o corpo uma dessas construções (PORTER, 1992).

Conforme Cooper (2007, p. 1551) salienta, a ideia de processo não tem fim e nem finalidade, simplesmente, gera-se como um movimento genérico: "É uma superfície na qual os órgãos e os sentidos do corpo se inscrevem de forma a refletir o corpo em seu contínuo trabalho de criar e recriar-se, como o puro processo de início e de vir a ser". Da mesma forma, Dale e Burrell (2000), também acreditam que o corpo é contingente, ao invés de universal e objetivo.

No que se refere a esse processo de ordenamento, Parker (2000) afirma que o conceito de organizing envolve padrões de alguma forma duradouros, pois quando organizamos algo sempre atribuímos uma forma, uma direção ou um sentido particular. Contudo, esses padrões não são perenes, de fato, o que torna o organizing um processo e não um produto acabado e finalizado. Cabe ressaltar que Parker (2000) não acredita que o organizing - como processo de construção social - seja realizado somente por humanos. De acordo com Parker (2000), todos nós somos cyborgs e nossos corpos só se realizam através de sua conexão com materiais não humanos, não existindo um dualismo entre as categorias corpo e organização. Parker (2000, p. 73) afirma que o corpo (independente do que a ideia de "corpo" inclui e exclui) na verdade é apenas um dos muitos lugares a partir dos quais poderíamos começar a pensar sobre organização. Na mesma linha de pensamento, Thanem (2001) ressalta esse movimento de combate ao antropocentrismo presente nas ciências sociais no processo de construção social do mundo, pelo qual a construção dos objetos é uma atribuição apenas dos humanos, afirmando ainda que, para Cooper, as coisas são ao mesmo tempo causa e efeito. Elas atuam e ao mesmo tempo sofrem atuações. O que é criado pelo homem volta-se contra ele e também o cria.

Rompendo com a ideia do realismo positivista e funcionalista, na qual o corpo é visto como entidade com fronteiras claras e bem definida, Dale e Burrell (2000) afirmam que o corpo pode ser reestruturado e que a imagem do self projetada pelo corpo pode ser recriada. Assim, o corpo deixa de ser visto unicamente como um sistema orgânico de partes interrelacionadas para ser visto com uma extensão do self, sendo a organização tanto uma extensão do corpo como o corpo uma extensão da organização.

Enfim, rompendo com a concepção de que corpo é apenas uma metáfora para a estrutura organizacional ou meramente um apêndice da máquina, Dale e Burrell (2000) esclarecem que as fronteiras bem definidas entre corpo e ambiente, tanto quanto as fronteiras entre mente e corpo, são colocadas à prova diante das condições de vida contemporâneas e das novas tecnologias desenvolvidas. Conforme Brewis e Sinclair (2000) afirmam, as relações que estabelecemos com nossos corpos são uma parte importante da forma como nos vemos e constituímos nossa subjetividade.

Dessa forma, o corpo não pode ser percebido apenas como biológico ou um receptáculo para a mente, mas sim como um objeto social em constante mudança (PEREIRA e AYROSA, 2012). Essa outra forma de se 
entender o corpo é denominada por alguns autores de embodiment. Flores-Pereira (2010, p. 418) esclarece que o conceito de embodiment concebe o corpo como algo que é bem mais do que uma representação, um objeto representacional, buscando "compreendê-lo como parte constitutiva da pessoa, um agente capaz de construir a história e a cultura do espaço onde habita".

Cabe destacar que o conceito de embodiment não concebe o corpo como neutro, passivo ou marca, nem acredita que existe a separação cartesiana entre corpo e mente. Como defendem Dale e Burrell (2014) em artigo recente, a noção de embodied person desvela as tensões e as contradições dentro da própria experiência de personificação humana, sem separação entre corpo e mente. $O$ corpo é ativo e não somente algo marcado pela cultura e a história; ou seja, o "corpo é um agente capaz de construir a história e a cultura do espaço onde habita, pois o corpo é parte constitutiva da própria pessoa" (FLORES-PEREIRA, 2010, p. 423). É por isso que o conceito de "embodied person" não pode ser desvinculado do conceito de "organized embodiment", uma vez que essa experiência precisa ser analisada a partir da dimensão coletiva da própria organização (DALE e BURRELL, 2014).

Sobre esse aspecto, Thanem (2003) crítica a hegemonia dos trabalhos da área de estudos organizacionais que tendem a enfatizar apenas as formas pelas quais os corpos são organizados, regulados ou normalizados, esquecendo-se de que o corpo também atua no processo de rompimento e resistência diante de padrões sociais hegemônicos.

Em relação ao conceito de embodiment, Letiche (2000) acrescenta que o corpo atua na constituição de múltiplas identidades, fragmentando a subjetividade. De forma simultânea, tanto o corpo quanto a subjetividade estão em constante processo de mudança (organizing), não se constituindo como algo fixo e acabado. Letiche (2000, p. 90) afirma que sua teoria não deseja "nem reificar o 'corpo' em uma concepção de 'forma' e nem em uma ideia de 'virtualidade' [mas que tenta] colocar o 'corpo' em um processo contínuo de vir 'a tornar-se'".

Assim, as fronteiras das organizações também passam a ser questionadas (CLEGG, 1990). Nesse sentido, as organizações contemporâneas caminham em direção a uma estrutura sem fronteiras, atuando em rede com outras organizações, governos e/ou comunidades, por exemplo. Dale e Burrell (2000) argumentam que o conceito de organização sem fronteiras - no que se refere à teoria organizacional - deveria ser visto de forma mais precisa como uma ameaça à hierarquia burocrática. A organização sem fronteiras não constitui uma ameaça à teoria organizacional se esta assume como preocupação maior o organizing e não a organização propriamente dita. Portanto, os autores deixam claro que objeto de análise dos estudos organizacionais é o organizing e não a organização, ressaltando que “'organização sem fronteiras' não é tanto uma organização sem limites ou estruturas, mas sim uma tentativa de redesenhar as fronteiras para tentar alcançar essa confluência de conhecimento e poder que tem sido há tanto tempo o objetivo de uma ciência racional" (DALE e BURRELL, 2000, p. 27).

Portanto, só faz sentido tratarmos o corpo como um tema dos estudos organizacionais quando passamos a entender que o objeto dos estudos organizacionais não são as organizações, mas o organizing. Em seu senso mais básico, organizing é o trabalho do corpo social generalizado que constitui a organização social; é ação composicional fundamental que vem antes da forma acabada ou objeto. Ferramentas e produtos desse processo devem ser entendidos como veículos para a construção contínua e movimento desse corpo social, em vez de individualmente identificável com estruturas delimitadas por fronteiras. A base do corpo social é, portanto, fonte de movimento contínuo e transmissão. E é exatamente o corpo social compreendido como uma estação de transmissão que nos ajuda a entender as organizações formais como produções de formas sociais. Nesse sentido, o corpo entendido como performance - não inerte, ativo, particular, subjetivo, contingente e histórico - vai de encontro ao objeto dos estudos organizacionais.

Cooper (2009) acrescenta que o corpo vive fora de si mesmo, eternamente procurando completar sua incompletude. Observa também que o seu contexto de existência é um campo generalizado de energia e ação no qual o corpo se reflete, transmitindo uma parte viva de sua ação social e cultural. Além disso, Cooper 
(2009) critica a definição do individual como um "eu" distinto dos outros "eus" formadores da sociedade. Para contrastar com essa ideia de individual, o autor traz o conceito de distância, explicando que a "ideia de distância sugere que o que chamamos de individual é permanentemente suspenso em uma ação dupla entre o corpo e o ambiente, entre o self e o outro, entre a parte e o todo" (COOPER, 2009, p. 243). Enfim, "o corpo humano é o caminho sensorial para a tradução e transmissão de forças corporais nas tecnologias cotidianas que apoiam e sustentam a vida social. O próprio corpo é uma parte integrante deste campo contínuo de ação" (COOPER, 2009, p. 243). Assim, o corpo não é uma coisa ou substância, mas a criação continua de eventos ou acontecimentos, como será explicitado a seguir.

\section{Corpo: um Constructo Social, Histórico e Cultural}

Foucault (1987) inicia sua análise sobre o processo de construção dos corpos sob as diferentes formas de disciplina, afirmando que o poder disciplinar atua diretamente na constituição dos corpos em nossa sociedade, tornando-os dóceis e úteis. Dessa forma, o corpo deixa de ser visto por esse filósofo como algo determinado pelo biológico, mas como uma construção histórica e social definida pelas relações de poder. Nesse momento, o que interessa para Foucault é problematizar como o corpo pode ser dividido, manipulado e reconstituído pela sociedade. Foucault denomina processo de objetivação esse investimento do poder na construção do corpo. Para Foucault (1987), o corpo é o "lugar onde as práticas sociais ínfimas e localizadas se relacionam com a grande organização de poder" (DREYFUS e RABINOW, 1995, p. 123). Já na biopolítica, Foucault (1999b; 2008) complementa suas análises sobre o corpo estudando os processos de subjetivação relacionados à sexualidade, evidenciando como o biopoder atua no e pelo corpo - bem como sua relação com a constituição da subjetividade humana -, rompendo com a clássica dicotomia mente-corpo.

Portanto, Foucault $(1987 ; 1999 b ; 2008)$ instaura a política do corpo. Isto é, ele intenta demonstrar na genealogia que o corpo está mergulhado no campo político, no qual as relações de poder operam nele e por ele; seja performatizando, treinando, preparando, suplicando, forçando ao trabalho ou constituindo seus gestos, cerimônias e signos. Como destacam Godfrey, Lilley e Brewis (2012, p. 544) em seu estudo sobre o corpo dos militares homens:

o self deve ser invocado como um veículo por meio do qual o controle é promulgado no corpo, [...] como tal, os exercícios de força sobre o "corpo social" são produtivos e não meramente repressivos: eles garantem que as coisas sejam feitas, que a ordem seja mantida e que o trabalho seja produtivo.

Obviamente, o corpo também está relacionado com o sistema econômico que objetiva tornar os homens produtivos e presos num sistema de sujeição, uma vez que esse corpo só se transforma em força útil se for, ao mesmo tempo, produtivo e submisso, "colocado num sistema de coação e de privação, de obrigações e de interdições" (FOUCAULT, 1987, p. 15). Contudo, o corpo não é algo passivo, atuando também na constituição subjetiva, uma vez que as punições impostas ao corpo devem atuar profundamente, embora, não apenas sobre ele, mas também "sobre o coração, o intelecto, a vontade e as disposições" (FOUCAULT, 1987, p. 20).

Podemos afirmar que esse ordenamento do corpo ocorre a partir do século XVIII, não se restringindo somente a torná-lo produtivo. Visa também classificá-lo e categorizá-lo em todas as suas capacidades através de uma divisão binária de gênero. Não é à toa que Laqueur (2001) afirma que a diferença entre os sexos surgiu nos séculos XVIII e XIX em função do momento político e filosófico da época, respectivamente, com o advento do Estado e da filosofia iluminista. Até o século XVIII, a anatomia do corpo não era considerada relevante para gerar diferenças entre seres humanos e classificá-los em dois sexos. Foucault (1988), ao estudar a sexualidade, demonstra que o corpo não é sexuado em nenhum sentido significativo, antes de sua 
determinação num discurso através do qual ele é investido de uma ideia de sexo natural e essencial. Pelo contrário, o corpo só ganha significado no discurso no contexto das relações de poder.

Nesse contexto histórico, o corpo passa a ser tratado como fundamental para categorizar a humanidade, sendo atribuídas aos indivíduos - a partir do seu corpo - características que vão além dos seus aspectos anatômicos, como, por exemplo, a capacidade lógica, presente nos homens, e a irracionalidade dos afetos, contida no corpo das mulheres. Aliás, Foucault (1987) também demonstra a articulação e disseminação em toda sociedade das tecnologias políticas do corpo e suas relações com o Estado e as instituições (escolas, hospitais, fábricas, exércitos, entre outras).

Contudo, como o poder opera de forma sutil e microfísica, quase imperceptivelmente, para que o mesmo passe despercebido ocorrerá uma biologização do corpo, na qual o corpo será visto como passivo, neutro e relacionado apenas à natureza biológica, intentando, assim, encobrir a realidade política do corpo.

Apesar de construído politicamente pelo poder, o corpo ainda é hegemonicamente visto como biológico, mesmo sendo, a todo momento, investido por políticas públicas de Estado. Tais políticas públicas propõem, por exemplo, ordenar as pessoas entre homens e mulheres para definir suas atribuições, capacidades e direitos. Propõe ainda controlar doenças, definir taxas de reprodução, bem como estabelecer qual é o corpo ideal para o trabalho, além de definir o que é um corpo saudável. Deve ser observado que, apesar da evidente presença de toda uma tecnologia específica de manipulação e formação do corpo, a este ainda é atribuído um determinismo biológico. Nesse sentido, o desafio é questionar essa visão hegemônica, desnaturalizando o processo e revelando os contornos de um corpo histórico.

No que diz respeito a um movimento de desnaturalização de um corpo eminentemente biológico, pode-se identificar e resgatar - para a área de gestão - algumas contribuições da história e de historiadores do corpo. Por exemplo, de acordo com Revel e Peter (1988, p. 141), "vivemos sem possibilidade de refletir sobre as aventuras de nosso próprio corpo [...] [a] sua evidência familiar e enganadora determina-lhe uma topografia positiva (diz-se natural) que, por sua vez, nos substitui o pensável”. Na busca pela superação dessa situação, Porter (1992, p. 308) defende a ideia de que se deve compreender o corpo sempre em seu sentido histórico, no interior de sistemas culturais particulares (privados e públicos), alterados no tempo:

[A] distribuição da função e da responsabilidade entre o corpo e a mente, o corpo e a alma, difere extremamente segundo o século, a classe, as circunstâncias e a cultura, e as sociedades com frequência possuem uma pluralidade de significados concorrentes. [O] estabelecimento do caso individual é um tema para ser negociado.

Ainda segundo Sant'Anna (2000, p. 225), "morada da alma, lugar dos pecados e do erro ou, ainda, relíquia que demanda conservação, tratamentos diferentes e valorização infinita, o corpo humano não cessa de ser redefinido ao longo dos séculos, de acordo com as expectativas e os limites de cada cultura". Assim, em total convergência com o pensamento foucaultiano, o corpo é constituído e controlado de forma disciplinar, fato que, ao não ser assumido, dificulta o entendimento do corpo contextualizado e histórico:

deixamos escapar metade da importância da disputa pela disciplina de horário nas fábricas, se a encararmos apenas em termos de racionalidade econômica e de heroicos capitães da indústria [Antes] de tudo, ela era parte de uma tentativa muito mais ampla de governar as pessoas, através do controle de seus corpos [...] Da mesma forma, seria limitado estabelecer os objetivos dos sanitaristas e dos higienistas apenas em termos de miasmas e drenagens: suas preocupações não eram menores com respeito à sujeira moral e à regulamentação do contágio e da contaminação sexual (PORTER, 1992, p. 313) 
Assim, os estudos sobre o corpo nos permitem melhor compreender o que uma dada sociedade (situada no tempo e no espaço) considera sujo ou limpo, saudável ou doente, forte ou fraco. Segundo Vigarello (2000, p. 229), o corpo é algo multifacetado que "pode representar dimensões bastante diferentes da vida [...] [e que] evoca numerosas imagens, múltiplas possibilidades de conhecimento. Além disto, o corpo é sempre algo inabarcável [...] sem dúvida o corpo é um arquivo".

No âmbito das ideias construcionistas sociais sobre o corpo, pode-se afirmar que existem duas grandes vertentes: uma que entende que o corpo é marcado e outra que acredita que corpo é performance (BUTLER, 2010). Para podermos entender melhor a construção social do corpo em torno desses dois conceitos, iremos nos concentrar a partir desse ponto nas intervenções feitas no corpo que produzem sentidos relacionados a gênero. Para a perspectiva da construção social do corpo como marca, o sexo (corpo) é determinado pela anatomia biológica com a qual nascemos, seja como homens ou mulheres, e somente gênero (masculino/feminino) seria um produto cultural. Vejamos as fotos a seguir:

Figura 1

\section{À esquerda, Dan Martinez e à direita, Marissa Martinez}

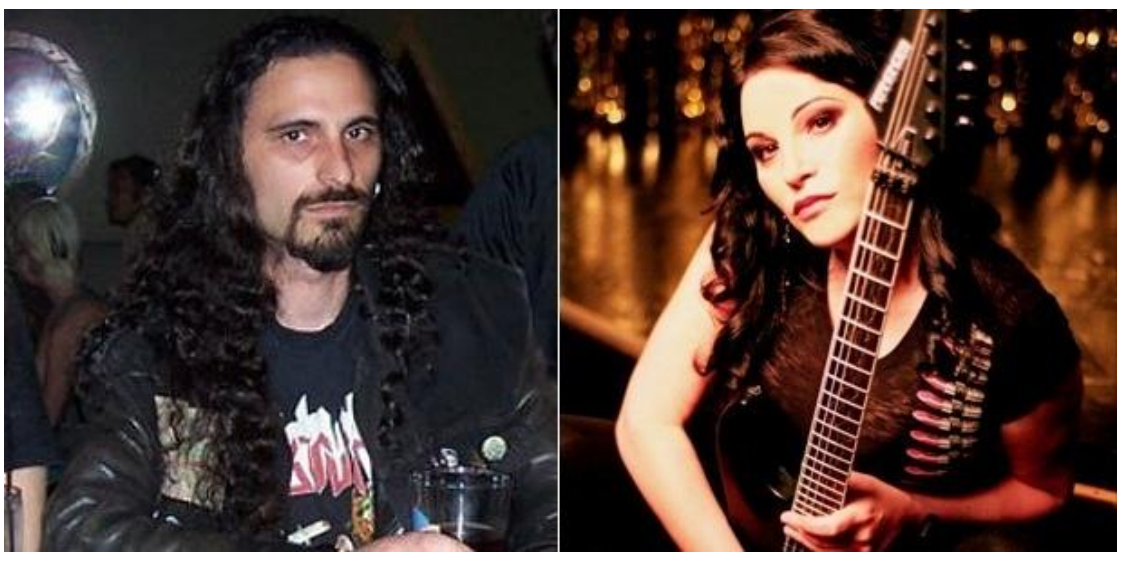

Fonte: Universo OnLine (UOL), 2012.

Figura 2

João Nery

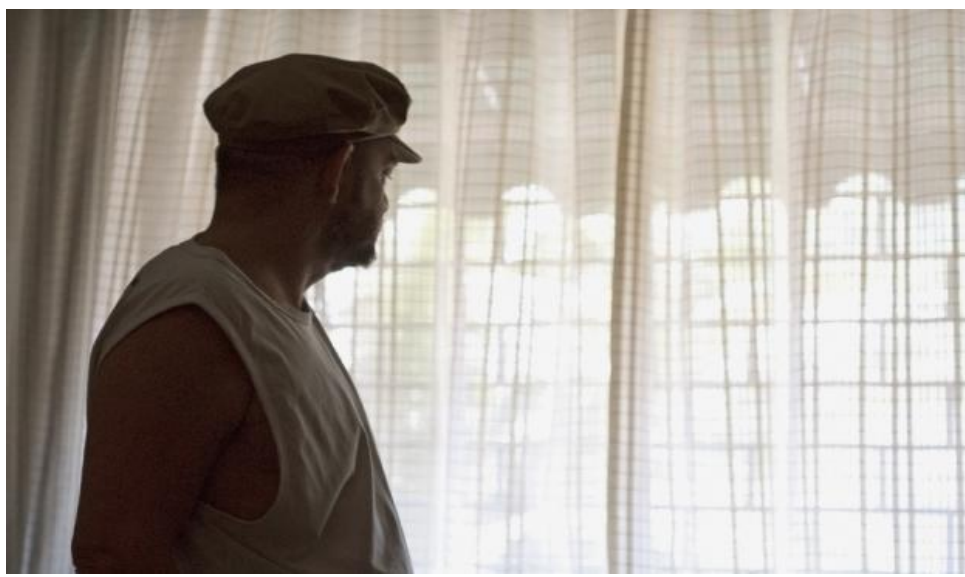

Fonte: Revista Trip, 2012. 
Se formos analisar o que define e diferencia homens e mulheres somente fundamentados na anatomia dos corpos, podemos afirmar que na figura 1 temos a foto de um homem à esquerda e de uma mulher à direita $\mathrm{e}$ na figura 2, a foto de um homem. Contudo, na figura 1 temos o guitarrista Dan Martinez, da banda de heavy metal Cretin, que há cinco anos decidiu incorporar a seu corpo a performance socialmente atribuída às mulheres e mudou seu nome para Marissa. Na figura 2 temos o oposto, trata-se da primeira mulher brasileira a incorporar características atribuídas à performance de homens. Portanto, vemos claramente como o corpo é uma construção em que lhe são estabelecidas determinados espaços, tempos e grupos; ou seja, o corpo é organizado e, desse modo, constitui-se pelo organizing.

Se analisarmos as figuras tendo-se como princípio a vertente de que o corpo é marcado, poderemos afirmar: o sexo (corpo) é determinado pela anatomia biológica com a qual nascemos, seja como homens ou mulheres, e somente gênero (masculino/feminino) seria um produto cultural. Tal crença, sexo biológico e gênero cultural, estão presentes na afirmação de Beauvoir (2009) de que não se nasce mulher, mas é a sociedade que torna o sexo feminino mulheres. Para Beauvoir (2009), o sexo (o corpo com sua anatomia) é biológico, ou seja, tem existência pré-discursiva; por sua vez, gênero é marca, um aprendizado cultural. Assim, para ela o gênero (cultural) marca o corpo (biológico), existindo uma relação direta entre sexo-gênero-sexualidade, na qual o sexo determina o gênero e, por sua vez, o gênero determina a sexualidade. Assim, a autora reafirma a construção social de que gênero é binário e que cada polo de gênero são opostos e incomensuráveis. Para Beauvoir, o gênero feminino (o Outro) é marcado, enquanto o masculino (o sujeito), por representar o universal, não o é.

Wittig (1985) concorda com Beauvoir ao defender que gênero são significados culturais assumidos pelo corpo sexuado (biológico), fazendo distinção entre sexo e gênero, na qual sexo é biológico e gênero é cultural, produzindo, assim, uma descontinuidade entre corpos sexuados e gêneros culturalmente construídos. Nessa concepção, o corpo é concebido como um meio passivo sobre o qual se inscrevem significados culturais que o marcam, operando sobre a clássica divisão e separação entre mente (subjetividade) e corpo. Desse modo, se formos analisar as figuras anteriormente apresentadas dentro da perspectiva de que corpo é marcado, os corpos demonstrados são passivos e dados a priori; ou seja, têm existência pré-discursiva, de forma que gênero operaria como uma marca social e histórica. Contudo, as vertentes mais recentes tratam o corpo como performance e não acreditam que gênero é uma marca realizada em um corpo inerte e passivo.

Para Butler (2010), o termo "homens" não se aplica exclusivamente a corpos masculinos e o termo "mulher" não está relacionado apenas a corpos femininos. Além disso, Butler (2010) e Louro (2008) claramente demonstram que gênero não é binário e cada categoria de gênero contém elementos de outras categorias que se constituem mutuamente, não sendo essas categorias autoexcludentes e opostas. Butler (2010, p. 25) afirma que "se o sexo é, ele próprio, uma categoria tomada em seu gênero, não faz sentido definir o gênero como a interpretação cultural do sexo. O gênero não deve ser concebido como a inscrição cultural de significado num sexo previamente dado (uma concepção jurídica) [...]".

Butler (2010) continua afirmando que gênero "não está para a cultura como o sexo para a natureza; ele [sexo] também é o meio discursivo/cultural pelo qual 'a natureza sexuada' ou 'um sexo natural' é produzido e estabelecido como 'pré-discursivo', anterior à cultura, uma superfície politicamente neutra sobre a qual age a cultura" (Ibid., p. 25). Assim, para Butler, sexo e gênero são a mesma coisa, sendo ambos produtos culturais; ou seja, para ela tanto sexo quanto gênero são performances. O "corpo é em si mesmo uma construção, assim como o é a miríade de 'corpos' que constitui o domínio dos sujeitos como marcas de gênero" (Ibid., p. 27).

Para Butler (2010), Foucault (1988), Louro (2008) e Scott (1986) não existe divisão entre mente e corpo, ambos são socialmente construídos e o corpo não é visto como algo inerte e passivo, atuando também na constituição subjetiva. Gênero não é uma marca que se efetua sobre um corpo biológico inerte, como acreditavam Beauvoir (2009) e Wittig (1985), mas uma performance histórica. O corpo não é uma "superfície pronta à espera de significação [...]", mas "um conjunto de fronteiras, individuais e sociais, 
politicamente significativas e mantidas" (BUTLER, 2010, p. 59). Sexo (corpo) é "uma predisposição performativamente ordenada [...], uma significação que, liberta da interioridade e da superfície naturalizadas, pode ocasionar a proliferação parodística e o jogo subversivo dos significados do gênero" (BUTLER, 2010, p. 59-60). Assim, se analisarmos as figuras anteriormente apresentadas com base nessa perspectiva, o sexo (corpo) é efeito e ação e não uma origem. Assim, o corpo nunca existe a priori ou pré-discursivamente, mas é sempre algo provisório, mutável e mutante (GOELLNER, 2007). Portanto, não devemos entender homem e mulher como uma categoria determinada pela anatomia biológica, mas como construções históricas, sociais e culturais envolvidas por relações de poder.

Em oposição a Beauvoir (2009) e Wittig (1985), Butler (2010) crítica a invocação de uma existência performativa de um antes não histórico que se constitui como a premissa básica para se garantir uma ontologia pré-social de pessoas. Para ela, ao analisar o objeto do feminismo, o termo mulheres deve ser problematizado, buscando-se entender como a categoria "mulheres" é produzida pelas relações de poder. A "tarefa é justamente formular no interior dessa estrutura constituída, uma crítica às categorias de identidade que as estruturas jurídicas contemporâneas engendram, naturalizam e imobilizam" (BUTLER, 2010, p. 22). Para Butler (1993), não existe relação direta entre sexo-gênero-sexualidade; ou seja, sexo não determina gênero e, por sua vez, gênero não determina sexualidade. Enfim, para a autora não existe identidade de gênero. Para Goellner (2007), o corpo também é uma performance; é uma construção nele estabelecida, sem que nada lhe seja "dado a priori, nem mesmo é universal: o corpo é provisório, mutável e mutante [...]" (Ibid., p. 28).

Portanto, um corpo não é apenas um corpo; é também o seu entorno. Mais do que um conjunto de músculos, ossos, vísceras, reflexos e sensações, o corpo é também roupa e os acessórios que o adornam, as intervenções que nele operadas, a imagem que dele se produz, as máquinas que nele se acoplam, os sentidos que nele incorporados, os silêncios que por ele falam, os vestígios que nele se exibem, a educação de seus gestos... Enfim, é um sem limite de possibilidades sempre reinventadas e a serem descobertas (GOELLNER, 2007, p. 29).

Diante do exposto, uma rápida análise das figuras 1 e 2 poderia nos levar a crer que os sujeitos estão realizando uma grande subversão ao modificarem seus corpos. Contudo, os mesmos as realizam dentro das categorias de sexo/gênero binárias socialmente construídas; ou seja, o fazem na e pela cultura, manifestando em seus corpos as relações de poder e os discursos sobre os corpos historicamente construídos, manifestando o processo de organizing que atua sobre os corpos. Isso significa dizer que nenhuma performance é livre. Como Butler $(1993 ; 2010)$ afirma a tarefa de distinguir sexo de gênero é dificílima, e a tarefa "torna-se ainda mais complicada quando entendemos que a linguagem da biologia participa de outras linguagens, reproduzindo essa sedimentação cultural nos objetos que se propõe descobrir e descrever de maneira neutra" (BUTLER, 2010, p. 160). Para a autora é o estranho, o que está fora da lei, que nos dá formas de compreender o mundo inquestionado de categorias sexuais como um mundo construído, e que pode, a todo momento, ser construído diferentemente.

\section{Considerações Finais}

Este artigo teve por objetivo problematizar o significado de organização por meio de uma análise construcionista do corpo, argumentando que o corpo é um tema de análise que pertence também ao campo dos estudos organizacionais. Durante esse percurso foi possível desvelar algumas possíveis implicações acerca dessa premissa sobre o conceito de organização.

Como objeto de análise dos estudos organizacionais, devemos considerar o organizing e não a entidade fixa e estática comumente denominada empresa. Assim, o campo de análise dos pesquisadores organizacionais é bem mais amplo do que apenas estudar fenômenos relacionados a empresas (entidades) ou ao trabalho. Sempre onde houver um ordenamento, um processo de organizar algo, impor uma direção e sentido (ou seja, 
um ordenamento), haverá o organizing, sendo esse o objeto de análise a ser considerado para os estudos organizacionais. O organizing ocorre tanto em empresas quanto na forma como se organizam bairros e comunidades. Contudo, o organizing não está preso a nenhuma dessas entidades, operando na sociedade como um todo através de relações de poder que constituem corpos, subjetividades e sentidos.

Em relação ao corpo, considerá-lo biologicamente natural é uma estratégia para considerá-lo algo neutro e passivo, que pode ser manipulado e passar como despercebido pelos estudos organizacionais. Considerar a constituição do corpo como pertencente às análises organizacionais significa considerá-lo como político e envolto por relações de poder.

\section{Referências}

ABBAGNANO, N. Dicionário de Filosofia. 2. ed. São Paulo: Martins Fontes, 2007.

BEAUVOIR, S. O segundo sexo: Tradução: Sérgio Milliet. 2. ed. Rio de Janeiro: Nova Fronteira, 2009.

BOAL, K. B.; HUNT, J. J. G.; JAROS, S. J. Order is free: on the ontological status of organizations. In: WESTWOOD, R.; CLEGG, S. Debating organization: point-counterpoint in organizations studies. Oxford: Blackwell Publishing Ltd., 2003.

BREWIS, J.; SINCLAIR, J. Exploring embodiment: women biology and work. In: HASSARD, J.; HOLLIDAY, R.; WILLMOTT, H. Body and organization. London: Sage Publications, 2000.

BURRELL, G. MORGAN, G. Sociological paradigms and organizational analysis: elements of the sociology of corporate life. Heinemann Educational Books, 1979.

BUTLER, J. Bodies that matter: on the discursive limits of "sex". New York: Routledge, 1993.

BUTLER, J. Problemas de gênero: feminismo e subversão da identidade. Rio de Janeiro: Civilização Brasileira, 2010.

CHIA, R. Ontology: organization as 'world-making”. In: WESTWOOD, R.; CLEGG, S. Debating organization: pointcounterpoint in organizations studies. Oxford: Blackwell Publishing Ltd., 2003.

CLEGG, S. Modern organizations. London: Sage, 1990.

COOPER, R. Organization/disorganization. Social Science Information, v. 25, n. 2, p. 299-335, 1986.

COOPER, R. Organs of process: rethinking human organization. Organization Studies, v. 28, n. 10, p. 1547-1573, 2007.

COOPER, R. The generalized social body: distance and technology. Organization, v. 17, n. 2, p. 242-256, 2009.

CUPANI, A. A crítica do positivismo e o futuro da filosofia. Florianópolis: Editora da UFSC, 1985.

CZARNIAWSKA, B. Social constructionism and organization studies. In: WESTWOOD, R.; CLEGG, S. Debating organization: point-counterpoint in organizations studies. Oxford: Blackwell Publishing Ltd., 2003.

DALE, K.; BURRELL, G. What shape are we in? Organization theory and the organized body. In: HASSARD, J.; HOLLIDAY, R.; WILLMOTT, H. Body and organization. London: Sage Publications, 2000.

DALE, K.; BURRELL, G. Being occupied: an embodied re-reading of organizational 'wellness'. Organization, v. 21, n. 2, p. 159-177, 2014. 
DONALDSON, L. Position statement for positivism. In: WESTWOOD, R.; CLEGG, S. Debating organization: pointcounterpoint in organizations studies. Oxford: Blackwell Publishing Ltd., 2003.

DONALDSON, L. Organization theory as positive science. In: TSOUKAS, H.; KNUDSEN, C. The Oxford Handbook of Organization Theory: meta-theoretical perspectives. 2. ed. Oxford University Press, 2011.

DREYFUS, H. L.; RABINOW, P. Michel Foucault, uma trajetória filosófica: para além do estruturalismo e da hermenêutica. Rio de Janeiro: Forense Universitária, 1995.

FLORES-PEREIRA, M. T. Corpo, pessoa e organizações. O\&S, v. 17, n. 54, p. 417-438, jul./set. 2010.

FOUCAULT, M. Vigiar e punir: história da violência nas prisões. Rio de Janeiro: Vozes, 1987.

FOUCAULT, M. História da sexualidade I: A vontade de saber. Rio de Janeiro: Edições Graal, 1988.

FOUCAULT, M. As palavras e as coisas: uma arqueologia das ciências humanas. São Paulo: Martins Fontes, 1999a.

FOUCAULT, M. Em defesa da sociedade. São Paulo: Martins Fontes, 1999b.

FOUCAULT, M. Estratégia, poder-saber. Rio de Janeiro, 2003.

FOUCAULT, M. Nascimento da biopolítica. São Paulo: Martins Fontes, 2008

GODFREY, R.; LILLEY, S.; BREWIS, J. Biceps, bitches and borgs: reading Jarhead's representation of the construction of the (masculine) military body. Organization Studies, v. 33, n. 4, p. 541-562, 2012.

GOELlnER, S. V. A produção cultural do corpo. In: LOURO, G. L.; FELIPE, J.; GOELLNER, S. V. (Orgs.). Corpo, gênero e sexualidade: um debate contemporâneo na educação. Rio de Janeiro: Vozes, 2007.

LAQUEUR, T. Inventando o sexo: corpo e gênero dos gregos a Freud. Rio de Janeiro: Relume Dumará, 2001.

LATOUR, B. Pandora's hope: essays on the reality of science studies. Cambridge, Massachussets: Harvard University Press, 1999

LETICHE, H. Situating complexity: the body (nude). In: HASSARD, J.; HOLLIDAY, R.; WILLMOTT, H. Body and organization. London: Sage Publications, 2000.

LOURO, G. L. Gênero, sexualidade e educação: uma perspectiva pós-estruturalista. Rio de Janeiro: Vozes, 2008.

MARRA, A. V.; BRITO, V. G. P. Construcionismo social e análise do discurso: uma possibilidade teóricometodológica. In: ENCONTRO DA ASSOCIAÇÃO NACIONAL DE PÓS-GRADUAÇÃO E PESQUISA EM ADMINISTRAÇÃO - EnANPAD, 35., 2011, Rio de Janeiro. Anais... Rio de Janeiro: ANPAD, 2011.

MORGAN, G. Imagens da organização. São Paulo, Atlas: 1996.

MOSCOVICI, S. A representação social da psicanálise. Rio de Janeiro: Zahar, 1978.

MUNRO, R. Unmanaging/Disorganisation. Ephemera: critical dialogues on organization, v. 1, n. 4, p. 395-403, 2001 .

PARKER, M. Manufacturing bodies: flesh, organization, cyborgs. In: HASSARD, J.; HOLLIDAY, R.; WILLMOTT, H. Body and organization. London: Sage Publications, 2000.

PEREIRA, S. J. N.; AYROSA, E. A. T. Corpos consumidos: cultura de consumo gay carioca, O\&S, v. 19, n. 61, p. 295-313, 2012.

PORTER, R. História do corpo. In: BURKE, P. A escrita da história: novas perspectivas. São Paulo, UNESP: 1992. 
REED, M. Teorização organizacional: um campo historicamente contestado. In: CLEGG, S. R.; HARDY, C.; NORD, W. R. Handbook de estudos organizacionais. São Paulo: Atlas, 1998.

REVEL, J.; PETER, J. P. O corpo: o homem doente e sua história. In: LE GOFF, J.; NORA, P. História: novos objetos. Rio de Janeiro, Francisco Alves: 1988.

REVISTA TRIP. Disponível em: <http://revistatrip.uol.com.br/revista/184/reportagens/corpo-estranho.html>. Acesso em: 22 dez. 2012.

SANT'ANNA, D. B. Apresentação. In: VIGARELLO, G. O corpo inscrito na história: imagens de um "arquivo vivo". Projeto História, São Paulo, n. 21, nov. 2000.

SCOTT, J. Gender: 'a useful category of historical analysis'. American Historical Review, v. 91, n. 5, p. 1053-1055, 1986.

THANEM, T. Processing the body: a comment on Cooper, Ephemera: critical dialogues on organization, v. 1, n. 4, p. 348-366, 2001.

THANEM, T. Contested and monstrous bodies, Ephemera: critical dialogues on organization, v. 3, n. 3, p. 250-259, 2003.

UNIVERSO ONLINE. Disponível em: <http://musica.uol.com.br/noticias/redacao/2012/12/21/pioneira-no-metalextremo-transexual-rompe-barreiras-mantem-urros-e-e-ate-cantada-por-fas.htm>. Acesso em: 22 dez. 2012.

VERGARA, S. C.; CALDAS, M. P. Paradigma interpretacionista: a busca da superação do objetivismo funcionalista nos anos 1980 e 1990. Revista de Administração de Empresas, v. 45, n. 4, p. 66-72, out./dez. 2005.

VIGARELLO, G. O corpo inscrito na história: imagens de um “arquivo vivo”. Projeto História, São Paulo, n. 21, nov. 2000.

WESTWOOD, R.; CLEGG, S. Debating organization: point-counterpoint in organizations studies. Oxford: Blackwell Publishing Ltd., 2003.

WITTIG, M. The mark of gender. Feminist Issues, v. 5, n. 2, p. 3-12, 1985. 